\title{
Atuação docente em Educação Física escolar: entre investimento e desinvestimento pedagógico
}

\author{
Sinara Pereira de Souza \\ Paulo Rogerio Barbosa do Nascimento² \\ Paulo Evaldo Fensterseifer ${ }^{3}$
}

\section{RESUMO}

O estudo investigou os componentes constituintes da cultura escolar de duas realidades escolares distintas, vivenciadas por uma professora colaboradora, considerando os perfis de atuação docente. De natureza qualitativa, esta pesquisa constitui-se num estudo de caso de caráter descritivo. Para a produção dos dados a pesquisa utilizou entrevistas semiestruturadas e diário de campo, cujas respostas foram categorizadas e analisadas de acordo com os fatores que influenciaram positiva e ou negativamente a atuação docente, comparando as realidades opostas vividas pela professora colaboradora. O estudo identificou que certos aspectos da cultura escolar tensionam a manutenção de um perfil de investimento pedagógico. Evidenciou, também, que além de aspectos pessoais e profissionais, e de um lugar assegurado e reconhecido pela disciplina de Educação Física na escola pelo conjunto dos membros da comunidade escolar, é fundamental a existência de um currículo fundamentado e o apoio pedagógico consistente e contínuo para garantir a manutenção do perfil de investimento pedagógico.

Palavras-chave: Cultura escolar. Educação física escolar. Docência em educação física

1 Acadêmica do curso de licenciatura em Educação Física da Universidade Regional do Cariri (URCA). Crato/ Ceará, Brasil. E-mail: souzasinara36@gmail.com

2 Mestre em Educação nas Ciências. Professor do departamento do curso de Licenciatura em Educação Física da Universidade Regional do Cariri (URCA). Crato/Ceará, Brasil. E-mail: paulorogerio.nascimento@urca.br

3 Doutor em Educação. Professor do Curso de Educação Física da Universidade Regional do Noroeste do Estado do Rio Grande do Sul (UNIJUI). Ijuí/Rio Grande do Sul, Brasil. E-mail: fenster@unijui.edu.br 


\title{
The teaching of Physical Education at school: between pedagogical investment and divestment
}

\begin{abstract}
This study investigated the components of the school culture in two distinct school realities, which were lived by a collaborative teacher, considering the profiles involved in active teaching. Characterized as a qualitative research, this study is a descriptive case study. For the production of data, the research made use of semi-structured interviews and a field diary, which were categorized and analyzed according to the factors that influenced positively or negatively the active teaching, by comparing the opposing realities lived by the collaborative teacher. The study identified that certain aspects of the school culture stress the maintenance of a profile characterized by pedagogical investment. It made evident, also, that besides certain personal and professional aspects, and the place ensured and acknowledged given to the subject of Physical Education in the school curriculum by the members of the school community, the existence of a curriculum which is reasoned and the existence of consistent and continuous pedagogical support to ensure the maintenance of the pedagogical investment profile are primal.
\end{abstract}

Keywords: School culture. Physical education at school. Teaching of physical education

\section{Atuacción docente en Educación Física escolar: entre inversiones y desinversiones}

\section{RESUMEN}

Este estudio investigó los componentes constituyentes de la cultura escolar de dos realidades escolares distintas vivenciadas por una profesora colaboradora considerándose los perfiles de actuación docente. De naturaleza cualitativa, esta investigación se constituye en un estudio de caso de carácter descriptivo. Para la producción de los datos, la investigación utilizó entrevistas semiestructuradas y diario de campo, los cuales fueron categorizados y analizados de acuerdo con los factores que influyeron positiva o negativamente la actuación docente, comparando las realidades opuestas vivenciadas por la profesora colaboradora. El estudio identificó que determinados aspectos de la cultura escolar tensionan la manutención de un perfil de inversión pedagógica. Asimismo, se evidenció que, además de los aspectos personales y profesionales, y de un lugar garantizado y reconocido por la asignatura Educación Física en la escuela, por el conjunto de miembros de la comunidad escolar, es fundamental la existencia de un currículo bien establecido y el apoyo pedagógico consistente y continuo para garantizar la manutención de inversión pedagógica.

Palabras clave: Cultura escolar. Educación física escolar. Docencia en educación física 


\section{INTRODUÇÃO}

A mudança de status da Educação Física (EF) enquanto componente curricular na escola, passando da condição de "atividade" para "disciplina", gerou a necessidade de investimento em produção curricular e em práticas pedagógicas, permitindo aos alunos o estudo e a apropriação de saberes da "cultura corporal de movimento" (BRACHT, 1992; BETTI, 1996). Esta dimensão do conhecimento comporta conhecimentos complexos e plurais, bem como organização didática e métodos de ensino específicos. $O$ atendimento dessas demandas faz parte dos desafios postos pelo "movimento renovador da EF" brasileira em suas produções pós-década de 80 do século passado.

O atual momento da EF escolar brasileira, conforme González e Fensterseifer (2009), se situa entre um "não mais" e o "ainda não". A expressão indica a descrença em paradigmas da EF que não dão conta das necessidades educacionais contemporâneas de uma sociedade democrática (em permanente reconstrução), tampouco da falta de consenso sistematizador em relação aos conteúdos e suas formas de tratamento na EF escolar. Assim, a EF brasileira estaria situada entre "algo" em que não se acredita mais, e "algo" que ainda não existe de fato, ou seja, um novo projeto de EF que tenha certo consenso.

No cenário do "ainda não" à afirmação de um caráter de disciplina curricular, pautado na ideia de leitura e ou compreensão de mundo, considerando conteúdos sistematizados e métodos de estudos que construam conhecimentos consistentes, o estudo se debruça sobre perfis de atuação docente. Destacam-se dois polos contraditórios": a) "Desinvestimento pedagógico" (ou abandono docente), que se caracteriza pelo não cumprimento das funções da docência e, em muitos casos, apenas administração do material pedagógico; b) "Investimento pedagógico", caracterizado pelo exercício constante das funções docentes, próprias à disciplina que ministra, e sua articulação com o currículo escolar.

São vários os elementos que, entrelaçados, concorrem para o surgimento e ou a manutenção dessas distintas situações relacionadas à atuação docente. Nesse cenário destacam-se dois elementos julgados importantes para a compreensão dessas situações: o primeiro elemento é justamente o processo de (re)significação do componente curricular, pautado nas críticas efetuadas por correntes progressistas à Educação Física tradicional, e que esbarram na ausência de efetivas proposições no âmbito escolar. O segundo elemento vincula-se à cultura escolar em torno da Educação Física e atravessa as duas situações. A cultura escolar de Educação Física pode ser entendida como os significados compartiIhados sobre os fins e o funcionamento desse componente curricular (GONZÁLEZ, 2008)5.

4 Esta caracterização pode ser entendida como "ideais tipos" no sentido weberiano, pois o mais frequente é encontrar situações híbridas que mesclam aspectos dessas posturas opostas. Existem, contudo, situações extremas que permitem essa diferenciação.

5 Comunicação realizada pelo professor Fernando Jaime González no Seminário sobre "Inovação e desinvestimento/ abandono do trabalho pedagógico na Educação Física escolar", intitulada: "A problemática da inovação e do abandono do trabalho docente em Educação Física: contextualização e aportes teórico-metodológicos” (UFES, Vitória, 27 de agosto de 2008, material mimeografado). 
A partir disso é possível apontar algumas questões norteadoras do estudo ${ }^{6}$, ou seja: quais fatores impactaram positiva ou negativamente a atuação docente de uma professora que vivenciou duas realidades escolares com características diferenciadas? Qual a relação desses fatores com a potencialização de intenções e/ou ações de investimento e de desinvestimento pedagógico nas duas realidades escolares vividas pela professora? E ainda: pode uma mesma pessoa ter comportamentos radicalmente distintos em sua atuação docente?

O objetivo do estudo foi investigar os componentes constituintes da cultura escolar de duas realidades escolares vivenciadas pela professora colaboradora e relacioná-los com a intencionalidade e a efetividade da atuação docente.

A justificativa da realização do estudo está amparada na necessidade de subsídios para a compreensão dos fenômenos de desinvestimento e de investimento pedagógico, de maneira contextualizada, numa dada região do país. A perspectiva é identificar elementos que possam dialogar e contribuir com a realidade da Educação Física, estabelecendo possíveis conexões com pesquisas que trataram e/ou estão tratando da temática em outros contextos socioculturais, acrescentando novos fatores na interpretação desses fenômenos.

Utilizou-se como referencial teórico básico da pesquisa, artigos científicos produzidos pelo grupo de investigação, denominado Rede Internacional de Investigação Pedagógica em Educação Física Escolar (REIIPEFE) ${ }^{7}$. Esse grupo estuda, entre outros, a cultura escolar e sua relação com o processo de investimento e de desinvestimento pedagógico ou abandono docente em Educação Física, considerando diferentes realidades socioculturais.

Entende-se que os conhecimentos produzidos pelos estudos dessa Rede de Pesquisa possam contribuir significativamente para melhor compreender a presença ou não dos fenômenos e os possíveis fatores atrelados, na realidade específica da região Sul do Estado do Ceará - Região Nordeste do Brasil, área de abrangência da Universidade Regional do Cariri (URCA). Destaca-se, outrossim, que o personagem dos distintos contextos em nenhum estudo até aqui realizado por esta Rede seja semelhante ao caso ora analisado. A situação permite capturar com maior acuidade o "fator contexto", contribuindo com mais elementos para compreender a complexidade desse fenômeno.

\section{PERCURSO METODOLÓGICO DO ESTUDO}

Trata-se de um estudo de caso com abordagem qualitativa e de caráter descritivo. O estudo de caso refere detalhadamente um fator não comum, ou seja, que não pode ser encontrado com o mesmo formato no universo populacional investigado (CERVO; BERVIAN; SILVA, 2007).

A colaboradora da pesquisa é uma professora que ministrou aulas em duas redes de ensino público, e que vivenciou duas experiências antagônicas: uma de sucesso e

6 Estudo financiado pelo Programa Institucional de Bolsa de Iniciação Científica (PIBIC) da Universidade Regional do Cariri (URCA) e desenvolvido no Núcleo de Estudo e Pesquisa em Educação Física do Departamento de Educação Física (NUPEF).

7 Disponível em: <http://reiipefe.hol.es/>. Acesso em: 02 dez. 2016. 
com realizações na prática da docência em EF, e outra com enfrentamentos da realidade, causando, em certa medida, frustração em relação ao fazer docente.

A professora colaboradora, ao iniciar a sua primeira experiência docente (considerada um sucesso), estava formada há 14 dias. A experiência durou um ano e três meses. A segunda experiência de atuação docente (em meio a dificuldades) teve início após um ano e três meses de sua formação. No momento da colaboração com a pesquisa a professora colaboradora já contava com um ano e quatro meses de atividades na sua segunda experiência docente, quando foi acompanhada pelos pesquisadores durante três meses consecutivos.

A produção dos dados durou três meses e ocorreu por meio de entrevista semiestruturada com a professora colaboradora e do seu acompanhamento da rotina escolar diária. Durante este período foram efetuados registros no diário de campo.

Inicialmente foi encaminhado documento para a escola, solicitando permissão para efetuar a pesquisa, juntamente com o Termo de Consentimento Livre e Esclarecido, que foi assinado pela diretoria e pela professora colaboradora.

Os dados a seguir apresentados foram organizados e analisados segundo três momentos distintos: $1^{\circ}$ ) Relato de uma experiência de sucesso na atuação docente em Educação Física; $2^{\circ}$ ) Demarcação e análise de fatores que impactaram a atuação docente da professora em sua experiência de insucesso a partir da identificação dos fatores que influenciaram na manutenção ou não do estado de investimento pedagógico; $3^{\circ}$ ) Comparação, demarcação e análise dos principais fatores da cultura escolar de Educação Física que foram conflitantes entre as realidade opostas vivenciadas pela professora em sua atuação docente, ou seja, uma experiência avaliada por ela como de "sucesso" e outra de "insucesso".

A análise dos dados faz referência a fatores concorrentes do investimento e ou do desinvestimento pedagógico, identificados na literatura produzida pela Rede Internacional de Investigação Pedagógica em Educação Física Escolar (REIIPEFE).

\section{INVESTIMENTO E DESINVESTIMENTO PEDAGÓGICO: CARACTERÍSTICAS E FATORES DETERMINANTES}

Investimento se caracteriza por uma aplicação que tem o intuito de obter resultados positivos, enquanto desinvestimento é a ausência dessa aplicação, e que não tem nenhuma pretensão de resultados (FERREIRA, 2000). Assim, investimento pedagógico requer atitudes de organização e direcionamento do processo de ensino com o intuito de obter resultados positivos no processo de ensino-aprendizagem. De uma forma mais direta seria alcançar os objetivos pré-estabelecidos.

Fensterseifer e Silva (2011, p. 121-122) apresentam em seu estudo, características determinantes de investimento pedagógico em Educação Física:

a) proposta pedagógica articulada com o currículo da escola; b) desenvolvimento de conteúdos de forma progressiva e com preocupação sistematizadora; c) envolvimento do conjunto dos(as) alunos(as) nas aulas; d) presença de conteúdos variados 
representativos da diversidade que compõem a cultura corporal de movimento; e) processos de avaliação articulados com os objetivos do componente curricular.

O desinvestimento pedagógico, por sua vez, é o oposto. É quando o professor "se nega" a tomar atitudes e a desempenhar seu papel, descumprindo a sua função e traindo os propósitos curriculares. As principais características são a ausência de planejamento que contemple a variedade de conteúdos pertencentes à especificidade da EF e a ausência de objetivos coerentes com a função da disciplina, concatenados com os da escola. Muitas vezes, o professor de EF apresenta práticas sem intencionalidades claras, cuidando dos alunos e dos materiais, compensando o "tédio dos alunos produzido nas outras disciplinas" (MACHADO et al., 2010, p. 132-133).

É imprescindível que para analisar investimento e desinvestimento pedagógico deve-se considerar os aspectos do contexto escolar em geral (LIMA JÚNIOR, 2012), os quais estão relacionados a esses fenômenos.

Ao analisar as pesquisas realizadas pelo grupo REIIPEFE foi possível evidenciar vários fatores que contribuem para ocasionar os fenômenos já citados, os quais são descritos a seguir:

- Fatores pessoais: esses fatores estão presentes antes mesmo da graduação. Dizem respeito às razões que levam a pessoa a cursar Licenciatura em EF. Sobre isso, Santos, Bracht e Almeida (2009, p. 144) relatam que "a decisão por qual profissão seguir é resultado do encontro de um conjunto de fatores culturais e sociais que, aliados às condições subjetivas, constituem a própria vida em construção". Embora possa não parecer determinante, esse fator acompanha o profissional por toda a sua carreira e é apontado como um dos responsáveis pela atuação docente.

- Tipo de formação: o tipo de formação, sem dúvida, repercute nas ações docentes, seja pelo que faz ou pelo que deixa de fazer, legitimando as escolhas do futuro profissional. Sem generalizar, mas apenas exemplificar, aqueles que tiveram uma formação esportivista tendem a pautar a sua prática pedagógica em moldes esportivos tradicionais. Já os que tiveram outra forma de abordagem do esporte, tal como propõe a perspectiva crítica desenvolvida por Kunz (2001 apud CARLAN; KUNZ; FENSTERSEIFER, 2012, p. 56), podem imaginar que:

[...] a escola se configura como um dos espaços de organização social onde as práticas esportivas acontecem, cabendo ao profissional da Educação Física proporcionar, pela tematização do seu conteúdo específico, uma compreensão crítica das práticas esportivas, potencializando os sujeitos a estabelecer vínculos com o contexto sociocultural em que estão inseridos.

Destarte, aqueles que tiveram "uma formação filosófico-humanista, epistemológica, científica, para além dos conhecimentos técnicos", como apontam Fensterseifer e Silva (2011, p. 131), terão grande probabilidade de tratar os conteúdos numa perspectiva crítico-reflexiva, tentando desenvolver o conhecimento para a formação integral dos alunos. 
- Formação continuada: a formação continuada é indispensável para que o profissional se mantenha atualizado sobre os avanços de sua área e para que continue refletindo sobre a sua prática a partir de novos aportes teóricos. A participação em grupos de estudos e cursos é uma opção para essas reflexões, pois ali compartiIham angústias e conquistas. Isto se torna ainda mais relevante ao se considerar os apontamentos feitos por Silva e Bracht (2012), de que a EF brasileira apresenta dificuldades em traduzir os avanços epistemológicos e teóricos para o campo da intervenção pedagógica. O fato foi evidenciado em uma pesquisa de Dessbesell e González (2011), em que uma professora, cujo perfil aponta para investimento pedagógico, apresenta dificuldades em promover a mediação entre o que "estuda" e suas aulas. A formação continuada poderia facilitar esse processo à medida em que um grupo maior dele se ocupasse, com capacidades diferentes de elaboração e de experiência com a prática docente.

- Reflexos da formação: a falta de clareza do professor sobre a importância, função e especificidade da Educação Física como componente curricular, assim como da própria escola, faz com que ele tenha dificuldades em desenvolver práticas renovadoras. O resultado disso é que a equipe pedagógica da escola também não visualiza a importância da disciplina no currículo, assim com os alunos, que podem até gostar do seu conteúdo, mas não conseguem dimensionar a possível contribuição da EF na sua formação pessoal. Não se estranha, portanto, que de uma formação precária resulte uma intervenção similar.

- Cultura escolar: Faria et al. (2010, p. 22) destacam que "O contexto escolar, por meio das ações dos sujeitos nesses espaços, forja determinada cultura particular que, de certa forma, estrutura as práticas geradas pelos atores escolares ao mesmo tempo em que é estruturada por elas". Logo, a maneira como a Educação Física é tratada pelos sujeitos da escola reflete a atuação do professor da disciplina, cujas ações influenciam o modo como os sujeitos escolares tratam a disciplina. O imaginário que daí resulta não é de ordem genética e tampouco produto de aprendizado com "alienígenas".

- Fatores atitudinais: alguns fatores estão diretamente relacionados às ações do professor, por exemplo: quando ele se nega a desenvolver um bom trabalho, ou quando não participa das reuniões de planejamento e se afasta das questões relacionadas à disciplina. Esse tipo de atitude o separa dos outros sujeitos escolares, fazendo-o "perder a voz" para cobranças de melhorias, resoluções de problemas ou para se impor, quando necessário. São ações negativas que culminam com a perda da credibilidade, e se repetem com relação à disciplina. As atitudes do professor possuem o poder, mesmo que relativo, de mudar a cultura escolar ou de perpetuar uma cultura pré-existente.

- Fatores profissionais: em meio a uma cultura escolar resistente a mudanças, os professores de Educação Física buscam satisfação/realização profissional a partir do reconhecimento do trabalho desenvolvido. Visam, assim, desenvolver o aprendizado do aluno, tornar a EF reconhecida como componente curricular na 
escola e, ainda, serem reconhecidos como professores que desenvolvem práticas inovadoras e identificadas com pressupostos teóricos críticos e reflexivos (FARIA; MACHADO; BRACHT, 2012).

Quanto à legitimação da disciplina, os professores que pautam as suas ações pedagógicas no investimento tendem a afirmar a sua especificidade e a buscar, constantemente, o seu reconhecimento como algo fundamental para o desenvolvimento humano, o que reflete na sua prática docente. Suas ações, portanto, estão "presas" ao reconhecimento da disciplina que, não existindo, podem fazer com que se sintam desestimulados, assumindo uma posição de desinvestimento pedagógico.

As relações desses fatores, bem como a presença ou ausência de algum deles, e as suas repercussões, sejam positivas ou negativas, se não forem determinantes para o investimento e ou desinvestimento pedagógico, parecem ser fortes indutores.

Os sete fatores supracitados estão atrelados à atuação docente de forma a influenciá-la e caracterizá-la. Compreendê-los, portanto, pode levar a desvendar fatores que sobressaem ou se inter-relacionam em determinados contextos escolares, contribuindo para experiências pedagógicas de sucesso. Ademais, demonstram situações de investimento pedagógico e servem de critérios para compreender determinados contextos de desinvestimento pedagógico. Enfim, podem potencializar intervenções propositivas que visem redimensionar a cultura escolar de Educação Física vigente em diferentes contextos.

\section{EXPERIÊNCIA DE SUCESSO: QUANDO A CULTURA ESCOLAR ERA OUTRA}

Ao se deparar com uma realidade escolar que a impactou negativamente, a professora de EF, colaboradora desta pesquisa, reagiu com um misto de desânimo e desafio, pois o parâmetro da experiência docente anterior tinha lhe trazido realização e a mantinha motivada, num constante processo de investimento pedagógico.

Nessa experiência de sucesso, as aulas de Educação Física eram no contraturno escolar. Conforme informações da professora colaboradora, os pais e a gestão escolar creditavam muita importância às aulas. A gestão escolar cobrava a participação dos alunos e declarava que poderiam reprovar na disciplina, tanto por ausência como por nota baixa.

A professora colaboradora relatou, ainda, que obteve apoio pedagógico complementar, que considerou essencial para o seu trabalho:

Além disso, havia um subsídio muito grande... é..., no aspecto pedagógico, por conta do sistema de professores formadores. (Entrevista com a professora colaboradora).

Evidencia-se que, neste caso, o apoio pedagógico e familiar se configurou como essencial para o bom desenvolvimento do trabalho. Isso repercutiu, inclusive, na maior adesão dos alunos às aulas, mesmo em um espaço que não era adequado, no caso, a quadra esportiva da comunidade.

A experiência de sucesso, segundo a professora colaboradora, se deu de forma articulada com uma política pública estruturada pela Secretaria Municipal de Educação de 
Petrolina/PE, e que previa um "Sistema de Professores Formadores". Cada disciplina tinha um ou mais professores formadores que eram responsáveis por acompanhar e auxiliar no seu desenvolvimento, além de "fiscalizar" se o professor estava desenvolvendo a proposta para aquele período, com base no que era acordado nas reuniões mensais, as quais contavam com os professores formadores e com os professores da disciplina.

Os Encontros de Formação Continuada adotavam uma proposta curricular em que havia uma sugestão de descritores ${ }^{8}$ vinculados a eixos temáticos distribuídos em unidades didáticas bimestrais e que contemplavam os esportes e jogos, a dança, a ginástica e as lutas. Todas as turmas, do $6^{\circ}$ ao $9^{\circ}$ ano, estudavam os mesmos eixos temáticos, numa perspectiva sequencial e progressiva quanto ao nível de complexidade do conteúdo. O professor até poderia acrescentar outros conteúdos e objetivos necessários, bem como temas transversais, no entanto, não deveria deixar de cumprir a proposta básica. As estratégias didáticas e metodologias, bem como planos de aula, também ficavam a cargo do professor.

Pelo fato de cada escola apresentar estruturas e realidades diferentes era aceitável que algum conteúdo e objetivo não se concretizasse, o que deveria ser justificado pelo professor. Ademais, todo o material didático era posto em debate e experimentação, e depois de aprovado pela escola ocorria um debate pautado na troca de experiências.

A Secretaria de Educação incentivava a troca de experiências não só nas reuniões mensais, como também nas feiras que aconteciam no final do ano, quando os professores costumavam apresentar os projetos e/ou propostas inovadoras que tiveram os melhores resultados. O intuito era enriquecer as propostas uns dos outros com ideias que deram certo e que poderiam ser aproveitadas pelos demais professores em outras escolas.

O currículo era flexível e objetivava organizar a disciplina no município, sem "prender" o professor, mas orientá-lo e direcioná-lo, dando-lhe liberdade para agir sobre ele, sem ignorá-lo. Esse material parecia trazer estabilidade e segurança para o professor, pois direcionava a sua proposta. Um currículo consistente, coerente e que contemple a especificidade da disciplina tem um papel fundamental na atitude docente da professora. Além disso, ter alguém responsável pela disciplina no município, que ordena propostas e requer a sua efetivação, reforça a sensação de responsabilidade com a disciplina.

Ao sintetizar as contribuições que mais influenciaram o desenvolvimento de um bom trabalho por parte da professora em sua experiência de sucesso, é possível evidenciar o apoio pedagógico que repercutiu na cultura escolar de maneira positiva, assim como o currículo/material didático que contemplou a especificidade da disciplina de maneira organizada.

\section{CONFLITOS PROFISSIONAIS: CULTURAS ESCOLARES OPOSTAS}

Em recente experiência com a docência em outra rede de ensino, a professora colaboradora vivenciou uma realidade contrária do relatado até o momento. A escola não

8 É o detalhamento de atitudes e habilidades a serem desenvolvidas em determinado conteúdo. 
possui estrutura física adequada para o desenvolvimento das aulas de EF, não tem apoio pedagógico, há distanciamento dos pais de alunos e ausência de um currículo consistente de EF, além de pouca adesão dos alunos às aulas. Mesmo assim a professora continuou demonstrando perfil de investimento pedagógico.

Não se relata, contudo, a experiência da professora colaboradora na docência da forma como ocorreu na descrição anterior, pois esta realidade vai se desnudando na medida em que os dados coletados vão sendo apresentados e analisados.

\section{a) Evidências de uma postura de investimento pedagógico}

Quando questionada sobre o seu entendimento de EF, a professora colaboradora pautou sua resposta no que considera importante e sobre o que ela entende da função:

[...] mas pelo menos eles experimentaram, pelo menos eles aprenderam alguma coisa, eu tive a chance de trabalhar com eles as questões morais e de permitir que eles descobrissem coisas novas, e de permitir, pelo menos, que eles criassem o hábito de se movimentar pra manter a sua saúde, por exemplo [...] Então a minha função... eu entendo a minha função como sendo essa. Permitir a eles a descoberta e a experimentação disso, do que é importante. (Entrevista com a professora colaboradora).

A fala da professora colaboradora explicita a sensação de contentamento com o mínimo, uma vez que as condições de trabalho são muito adversas. Para ela, se conseguir o pouco já é "melhor que nada". Mesmo não apresentando um conceito direto e mais completo com base na literatura da EF, a professora compreende a disciplina a partir de elementos que acredita estarem atrelados à sua função. Em sua fala revela aspectos vinculados ao tipo de formação que teve e sustenta a sua convicção de que precisa ampliar as experiências de seus alunos nesta área de conhecimento (reflexos da formação).

A professora colaboradora mostrou-se descontente com a forma como a disciplina de EF é ministrada na escola atual. Demonstra indignação por não haver horários reservados para cada aula, conforme as séries escolares, e por serem no contraturno escolar, com várias turmas agrupadas. Frustra-se ao entender que não consegue cumprir com os objetivos educacionais. Dessa forma, revela reflexos da sua formação profissional, reconhecendo a EF como componente curricular que deve somar no cumprimento dos objetivos da educação escolar.

Diante dessa situação desfavorável em relação às suas expectativas, a professora colaboradora procurou demarcar junto aos alunos e à gestão escolar, a função e a importância de sua disciplina. Buscou mostrar que a disciplina é equivalente aos demais componentes curriculares tanto no aspecto legal como no pedagógico. Fez várias investidas com os alunos e a gestão escolar, buscando o reconhecimento da sua função docente, sem o qual fica difícil a satisfação e a realização das suas atividades. Este reconhecimento é um fator profissional fundamental para que haja estímulo em relação à manutenção do estado de investimento pedagógico. Isso ficou demarcado na fala da professora colaboradora: 
Mas vai chegar um momento que a verdade vai ser essa: ou muda ou eu vou embora, porque da forma que tá lá, a impressão que dá, é que a Educação Física, da forma como tá posta naquela escola, não é pra aquela pessoa competente. É pra um professor incompetente que quer ficar sem fazer nada. (Entrevista com a professora colaboradora).

A professora relata que levou bolas de vários esportes para a quadra, e de ter fixado no mural de avisos da escola assuntos relativos à disciplina, além de ter feito uma aula inaugural. Essas ações caracterizam um fator atitudinal de enfrentamento da situação vivenciada, que tiveram repercussão na cultura escolar, pois os alunos se tornaram mais participativos e interessados. Uma mudança pequena mas que a motivou a seguir com as atividades.

Outras atitudes dizem respeito à inserção de novos conteúdos nas aulas, ou à apresentação de uma nova proposta da disciplina de Educação Física na gestão escolar, na tentativa de obter apoio pedagógico e, com isso, conseguir mudanças mais significativas para a Educação Física na escola. Um exemplo é conquistar a autonomia para realizar avaliações, e ter uma aula no mesmo turno para possibilitar o acesso a todos os alunos.

[...] numa adaptação próxima ao ideal, que é a proposta nova pra 2015, que é uma aula no turno, outra aula no contraturno, mesmo que em outro ambiente de outra escola ou na quadra da comunidade é viável e funcionaria muito bem. (Entrevista com a professora colaboradora).

Esse conjunto de iniciativas com vistas a melhorar as condições de trabalho e as demais ações realizadas pela professora colaboradora se relaciona com a necessidade de reconhecimento social, condição fundamental para a "autonomia e autorrealização dos indivíduos" (HONNETH apud FARIA et al., 2010, p. 21). Este objetivo também está relacionado a uma questão de direito, visto que no caso da professora colaboradora, esta não possui asseguradas as condições mínimas para o cumprimento daquilo que socialmente é seu dever. Também se encontram prejudicadas as questões de solidariedade quando não há o respeito mútuo no sentido da escuta e do diálogo entre colegas de profissão e alunos (FARIA; MACHADO; BRACHT, 2012). Quando este reconhecimento não ocorre, uma das tendências é lutar para que ele seja conquistado, o que auxilia a compreender a razão de a professora ainda se manter em situação de investimento pedagógico apesar das condições adversas.

Em seus estudos, Faria, Machado e Bracht (2012) percebem que tanto professores em situação de investimento como em desinvestimento pedagógico sofrem desrespeito nas dimensões do direito e da solidariedade. Boa parte desse desrespeito é creditado a uma suposta condição de inferioridade da $E F$, pois é colocada num patamar em que é questionada e ou não valorizada quanto à sua contribuição na educação escolar. 


\section{b) Condições potencializadoras do desinvestimento pedagógico}

A falta de apoio na reestruturação da disciplina para o desenvolvimento de novas propostas e a desvalorização da disciplina trouxeram repercussões negativas para a atuação da professora, como está explícito na fala que segue:

Agora no fim do ano quando eu fui dizer que gostaria de pôr uma aula no turno e tal, eu já recebi a 'negativa' [...]. Isso é um problema muito sério, um problema de comunicação que é praticamente impossível concluir uma frase, sabe? E... é muito difícil de ser escutada, e... ter essas ideias respeitadas, o que você fala respeitado. Um dos piores problemas. (Entrevista com a professora colaboradora)

O entendimento dos alunos em relação à disciplina se deve, segundo a professora colaboradora, à forma como ela vem sendo conduzida por outros professores. São várias atitudes que levam ao desinteresse dos alunos em relação ao conteúdo da disciplina, como tratamento depreciativo do professor, aulas no contraturno para mais de uma turma ao mesmo tempo, disciplina sem horários reservados com cada turma separadamente, falta de horários regulares, não permitindo a sistematização progressiva dos conteúdos, entre outros.

Sobre a maneira como a direção, a coordenação e os colegas de trabalho percebem a disciplina de EF, a professora colaboradora faz os seguintes comentários:

A direção enxerga como um problema, realmente um problema, assim, algo que, é... a direção acha, assim, que não tem estrutura suficiente pra garantir que seja uma boa Educação Física, então prefere não se incomodar com isso. Utiliza a desculpa de: ah, mas não tem condição, então deixa assim da forma que está. E eu percebo que a direção é muito resistente a sair da zona de conforto, né?

[...] A coordenação não entende muito bem, assim, da coisa em si, mas as propostas são apresentadas, né? São analisadas pela coordenação e geralmente, é... é... elas são bem vistas, assim, né? Porque a coordenação ela vê mais o lado pedagógico da coisa, então ela procura enxergar o benefício pedagógico daquilo que eu tô propondo.

É... entre os colegas, professores, isso varia muito. Eu tenho professores que... eu tenho colegas que chegam e dizem: mudou muito viu, depois que você chegou a gente já viu a mudança. Que dão os parabéns quando se realiza algum projeto e tal. Têm outros que se incomodam, se incomodam porque eu tô sempre entrando nas salas pra dar avisos, e realmente isso incomoda, é chato, né? E se incomodam porque os meninos ficam eufóricos. (Entrevista com a professora colaboradora).

É... totalmente fora do que eu tava habituada porque eu vim duma realidade que eu tava muito satisfeita, [...] E eu, de repente, eu tive um choque com a realidade que era totalmente diferente, onde eu não era valorizada, onde a minha disciplina era, assim, nas palavras da direção era 'o rebotalho da escola'. Então, foi um choque, foi triste [risos]. (Entrevista com a professora colaboradora).

As falas da professora colaboradora também revelam um estado de saturação: 
No momento, com essa realidade de agora, eu estou de saco cheio, eu não vejo a hora de chegar as minhas férias, não quero nem mais... [...] se dissesse [...] escolha agora, você quer ir pra escola até o dia 19 que é o dia que entra de férias ou quer ficar em casa? Eu dizia: eu quero ficar em casa, não piso aqui mais, nem obrigada, eu estou de saco cheio de ficar lá sentada olhando pra parede. Não aguento mais isso, tô de saco cheio. (Entrevista com a professora colaboradora).

Esse estado de saturação da professora colaboradora concorre negativamente para a manutenção de uma postura de investimento pedagógico, desgastando-a pessoal e profissionalmente. Compreende-se que a sua postura é de resistência às condições adversas do seu trabalho, e passa a não ceder totalmente ao caráter funcional de uma possível postura de desinvestimento pedagógico, que se caracteriza por "fazer o jogo" já aceito pelos atores da comunidade escolar (gestão escolar, alunos e familiares), minimizando os desgastes de possíveis enfrentamentos dessa cultura escolar (PICH; SCHAEFFER; CARVALHO, 2013).

\section{CONFRONTO ENTRE REALIDADES}

O presente estudo apresentou, num primeiro momento, o relato de uma realidade escolar que contribuiu para a atuação docente de sucesso. Posteriormente, num segundo momento, foram analisados dados que demarcaram o perfil de investimento docente da professora colaboradora mesmo diante de uma realidade adversa. Identificou-se os fatores dessa realidade que Ihe causaram situação de estranheza e que a desestabilizaram em seu fazer cotidiano, levando-a ao desgastante enfrentamento de uma específica cultura escolar de EF.

Passa-se, agora, a comparar as duas realidades escolares vivenciadas pela professora colaboradora para perceber os aspectos que contrastaram significativamente e que concorreram para criar condições de reforço ao estado de investimento pedagógico e ou impactaram a professora, desgastando-a no processo de manutenção do seu perfil de atuação docente. Neste sentido, atenta-se para fatores da cultura escolar como um todo e não somente a fatores pessoais, atitudinais e de formação da professora, pois esses já ficaram evidenciados anteriormente.

O reconhecimento do componente curricular de EF, que possibilite assegurar os horários de aula para o cumprimento do currículo, e permita avaliar os saberes, desfaz um mal-estar denunciado por Kunz (1994), que é o fato de se ressentir de um currículo e de seus fazeres coerentes. Esse fator foi fundamental para nortear as ações da professora colaboradora em sua experiência de sucesso.

Já em sua experiência de insucesso, o currículo não seria um problema mas sim a pouca importância dada ao cumprimento de um planejamento, manifestada na ausência de horários de aula para cada série, e a falta de uma avaliação coerente. Um estado de coisas que levou a professora colaboradora a colocar a culpa, num primeiro momento, na docente que lhe tinha antecedido: 
[...] e me chocou saber que ela é tão próxima, que ela se formou na mesma turma desses professores e é... faz parte da mesma universidade que eu, com os mesmos princípios com o qual eu fui formada e tava trabalhando dessa forma, assim. Aí eu me questionei depois se isso não era por conta das pressões da direção, mas aí eu lembrei de ela dizer: nem tente porque eles não fazem. (Entrevista com a professora colaboradora).

Durante a atuação da professora colaboradora na escola, a ausência de apoio pedagógico constante, diferente da experiência anterior, foi um fator impactante. Mesmo assim, como se evidenciou anteriormente, a professora buscou criar condições para possibilitar a aproximação desse apoio pedagógico, sem obter sucesso. Essa falta de apoio pedagógico que sente a professora colaboradora encontra precedentes em outros docentes que apresentam perfil de investimento docente e que também ficam impactados com esta ausência. A necessidade de compartilhamento das questões que permeiam o cotidiano da escola, assim como a troca de informações sobre os fazeres, as dúvidas e possíveis encaminhamentos didáticos, estão na base dessa queixa (FENSTERSEIFER; SILVA, 2011).

Já a falta de materiais, segundo a professora colaboradora, não é considerada um problema, pois na outra realidade vivenciada anteriormente essa mesma necessidade não foi um fator determinante para o não cumprimento dos objetivos da disciplina.

Outro fator que mereceu destaque na relação de sucesso e insucesso pedagógico foi o fato de em uma realidade haver aproximação entre família e escola, e uma consequente valorização do professor pela comunidade. Enquanto isso, na outra realidade há uma significativa ausência da participação familiar, o que, segundo a percepção da professora colaboradora, compromete a relação professor-aluno pela não valorização e respeito, condições essenciais para a docência.

\section{CONCLUSÕES}

O presente estudo confirma a complexidade do tema, e permite apontar algumas considerações conclusivas acerca do caso analisado. De acordo com os estudos da REIIPEFE, que serviu de referência principal, é possível afirmar que os professores de Educação Física estão sujeitos a transitarem entre um polo (investimento pedagógico) e outro (desinvestimento pedagógico), com permanências ou não. No caso em questão o quadro se confirma em uma só pessoa, pois embora aponte para uma situação de investimento, está muito próxima de um caso de desinvestimento.

Entre os vários fatores influenciadores do perfil de atuação profissional, alguns dizem respeito a questões de cunho mais pessoal e formativo, assim como aspectos estruturais da organização e convicções que vão se estabelecendo entre os atores escolares, tais como: tipo de formação inicial e seus reflexos; formação continuada; cultura escolar, em particular os relativos à EF; fatores atitudinais e fatores profissionais. Este conjunto de fatores influencia a prática docente de tal maneira que o perfil de atuação profissional vai se compondo a partir de suas inter-relações. 
Evidencia-se neste estudo o dilema vivenciado por uma professora, cujo perfil de atuação docente se mantém como de investimento pedagógico, mesmo diante de uma realidade impactante para a manutenção desse perfil.

Acredita-se ter demonstrado que certos aspectos da cultura escolar, considerados negativos para a manutenção de um perfil de investimento pedagógico, estão saturando a professora, exigindo-lhe um esforço muito grande para manter o seu perfil docente, forçando-a sobremaneira a um possível deslocamento do polo de investimento para o do desinvestimento pedagógico. Já os aspectos considerados positivos contribuíram consideravelmente para que a professora se mantivesse num perfil de investimento pedagógico e se autorrealizasse na sua função docente.

O estudo evidenciou que além de aspectos pessoais e profissionais, bem como um lugar assegurado para a disciplina de EF na escola, reconhecido pelo conjunto dos membros da comunidade escolar, há necessidade de um currículo fundamentado e um apoio pedagógico consistente e contínuo, os quais são fundamentais para a manutenção de um perfil de investimento pedagógico.

O enfrentamento de uma situação conflituosa como a analisada neste estudo é desgastante e de difícil superação individual. Neste sentido, mesmo estudos com delineamento mais propositivo, na ótica da pesquisa-ação, embora necessários à realidade investigada, seriam insuficientes se não contemplassem o conjunto da comunidade escolar. Reforça-se neste estudo que a compreensão e a construção de processos coletivos de enfrentamento de uma "cultura escolar" de Educação Física resistente a mudanças pode contribuir para gerar rupturas com o "estabelecido" e permitir inovações e a consequente legitimação da EF como um componente curricular na Educação Básica.

Este enfrentamento é fundamental para que não se exija atitudes "heroicas" dos professores, mas se invista em condições para que possam melhor utilizar o seu tempo, atuando no processo educacional a partir da especificidade de sua disciplina, ao invés de gastá-lo na tentativa de criar, isoladamente, as condições para poder atuar. Enfim, se a escola é um espaço coletivo, seus sucessos e insucessos também derivam, em boa medida9, das ações desse coletivo.

\section{REFERÊNCIAS}

BETTI, M. Por uma teoria da prática. Revista Motus Corporis. Rio de Janeiro, 1996, v. 3, n. 2, pp. 73-127.

BRACHT, V. Educação Física e aprendizagem social. Porto Alegre: Magister, 1992.

CARLAN, Paulo; KUNZ, Elenor; FENSTERSEIFER, Paulo Evaldo. O esporte como conteúdo da Educação Física escolar: estudo de caso de uma prática pedagógica "inovadora". Movimento. Porto Alegre, out./dez. 2012, v. 18, n 4, pp. 55-75.

9 Não se trata, no entanto, de desresponsabilizar os professores naquilo que depende de suas ações individuais e nem ignorar os determinantes socioeconômicos de natureza mais ampla. 
CERVO, Amado Luiz; BERVIAN, Pedro A.; SILVA, Roberto da. Metodologia científica. São Paulo: Pearson, 2007.

DESSBESELL, Giliane; GONZÁLEZ, Fernando Jaime. O envolvimento de docentes com diferentes perfis de atuação no processo de (re) formulação coletiva do plano de estudo da disciplina de Educação Física em uma escola de educação básica. SIC-XIX Seminário de Iniciação Científica. Relatório apresentado ao Comitê Científico da Universidade Regional do Noroeste do Estado do Rio Grande do Sul. Anais... Ijuí, RS: Unijuí, 2011.

FARIA, Bruno de Almeida; BRACHT, Valter; MACHADO, Thiago da Silva; MORAES, Cláudia Emília Aguiar; ALMEIDA, Ueberson Ribeiro; ALMEIDA, Felipe Quintão de. Inovação pedagógica na Educação Física: O que aprender com práticas bem sucedidas? Ágora para la EF y el Deporte, 2010, v. 1, n. 12, pp. 11-28.

; MACHADO, Thiago da Silva; BRACHT, Valter. A inovação e o desinvestimento pedagógico na Educação Física escolar: uma leitura a partir da teoria do reconhecimento social. Motriz. Rio Claro, SP, jan./mar. 2012, v. 18, n. 1, pp. 120-129.

FENSTERSEIFER, P.E.; SILVA, M.A. Ensaiando o "novo" em Educação Física escolar: a perspectiva de seus atores. Rer. Bras. Ciênc. Esporte. Florianópolis, jan./mar. 2011, v. 33, n. 1, pp. 119-134.

FERREIRA, Aurélio Buarque de Holanda. Miniaurélio século XXI: o minidicionário da língua portuguesa. 4. Ed. Ver. E ampliada. Rio de Janeiro: Nova Fronteira, 2000.

GONZÁLEZ, F.J. A problemática da inovação e do abandono do trabalho docente em Educação Física: contextualização e aportes teórico-metodológicos. Seminário sobre Inovação e desinvestimento/abandono do trabalho pedagógico na Educação Física escolar. Anais... Vitória: UFES, 27 ago. 2008 (Mimeo).

; FENSTERSEIFER, P.E. Entre o "não mais" e o "ainda não": pensando saídas do não-lugar da EF escolar I. Cadernos de Formação RBCE. Florianópolis, 2009, v. 1.

KUNZ, Elenor. Transformação didático-pedagógica do esporte. ljuí, RS: Unijuí, 1994.

LIMA JÚNIOR, Yuri Moreira de. Investimento/desinvestimento pedagógico: compreendendo características da docência em Educação Física que podem levar o professor a investir/ desinvestir no trabalho. Trabalho de conclusão de curso (Graduação em Educação Física) - Universidade Federal do Rio Grande do Sul. Porto Alegre: UFRG, 2012.

MACHADO, Thiago da Silva et al. As práticas de desinvestimento pedagógico na Educação Física escolar. Movimento, abr./jun. 2010, v. 16, n. 2, pp. 129-147.

PICH, S.; SCHAEFFER, P.A.; CARVALHO, L.C. O caráter funcional do abandono do trabalho docente na Educação Física na dinâmica da cultura escolar. Revista Educação. Santa Maria, RS, set./dez. 2013, v. 38, n. 3, pp. 631-640.

REIIPEFE. Rede Internacional de Investigação Pedagógica em Educação Física Escolar. Disponível em: http://reiipefe.hol.es/. Acesso em: 02/12/2016.

SANTOS, Núbia Zorzanelli dos; BRACHT, Valter; ALMEIDA, Felipe Quintão de. Vida de professores de Educação Física: o pessoal e o profissional no exercício da docência. Movimento. Porto Alegre, abr./jun. 2009, v. 15, n. 2, pp. 141-165. 
julho/2018

SILVA, Mauro Sérgio da; BRACHT, Valter. Na pista de práticas e professores inovadores na Educação Física escolar. Revista Kinesis. Santa Maria, jan./jun. 2012, v. 30, n. 1, pp. 80-94.

Recebido em: Março/2017

Aprovado em: Agosto/2017 